\title{
Potentiation of 'late' responses evoked in muscles during effort
}

\author{
A. R. M. UPTON ${ }^{1}$, A. J. McCOMAS ${ }^{1}$, AND R. E. P. $\operatorname{SICA}^{2}$ \\ From the National Hospital for Nervous Diseases, Maida Vale, London, and the Regional Neurological Centre, \\ Newcastle General Hospital, Newcastle upon Tyne
}

SUMMARY A study has been made of the effect of voluntary contraction on the 'late' responses which can be recorded in muscles after indirect stimulation. Two late responses have been described of which the first was shown to consist mainly of a potentiated H-reflex. The potentiation of this wave was greatest in the abductor pollicis brevis muscle and depended largely on 'direct' descending pathways to motoneurones. In addition, a later evoked muscle response appeared during effort; the nature of this wave was uncertain. Simple formulae have been devised to express the excitability of motoneurones to inputs from muscle nerves during effort.

The present study is concerned with changes in the excitability of human motoneurones during voluntary muscular contraction. Our aim has been to devise a method for testing excitability which could be applied to virtually any group of motoneurones innervating limb muscles. It was hoped that such a technique would prove of value in the investigation of lesions involving descending motor pathways.

It has long been known that, in the case of calf muscles, motoneurone excitability may be readily tested by electrical stimulation of the medial popliteal nerve. Thus, after a submaximal stimulus to this nerve both early and late responses can be recorded from gastrocnemius and soleus muscles. Hoffmann (1918) showed that, whereas the first (or $M$ ) wave was due to direct stimulation of motor axons, the second discharge resulted from reflex excitation of motoneurones by afferent fibres from muscle. Magladery and McDougal (1950) called this second wave an ' $H$ '-reflex after Hoffmann and subsequently Magladery, Porter, Park, and Teasdall (1951) showed that the reflex was probably a monosynaptic one. From animal studies it is likely that the afferent fibres concerned are the large diameter ones from annulospinal endings in muscle spindlesthat is, Ia fibres; see Lloyd (1943). An important characteristic of the H-reflex response is that it

'Present address: Neurology Section, McMaster University Medical Centre, Hamilton 16, Ontario.

2Present address: Hospital Ramos Mejia, Buenos Aires, Argentina. declines as the stimulus to the nerve is increased beyond a certain level; at the same time the $M$ wave increases. This reduction in the H-reflex is due to collision between antidromic and reflexly-elicited impulses in motor axons.

Although H-reflex testing is an extremely convenient method for estimating motoneurone excitability, it is unfortunately not normally possible to demonstrate these reflexes in muscles other than those of the calf and sole. However, in these other muscles a small and variable late response can be evoked by maximal or supramaximal nerve stimulation; this response was called the $\mathrm{F}$ wave by Magladery and McDougal (1950). Dawson and Merton (1956) found that impulse conduction velocities in motor fibres were the same as those in $F$ wave fibres, when measured over long segments of the ulnar nerve.

These authors suggested that the $F$ wave was due to a small recurrent discharge of a few motoneurones produced by an antidromic volley in the motor fibres (Renshaw, 1941). Thorne (1965) also obtained evidence of an antidromic mechanism; he recorded potentials from single motor units in more than $\mathbf{3 0}$ normal subjects and found that those units contributing to the $F$ wave had invariably discharged during the preceding $M$ wave. Another approach has been to cut dorsal roots in the cat (Gassel and Wiesendanger, 1965) and in the baboon (McLeod and Wray, 1966). In both species the persistence of 
an $\mathbf{F}$ wave indicated the existence of an antidromic component in its genesis. Similarly, in man it has been shown that the response can still be elicited after dorsal root section and that it then becomes larger and less variable in amplitude (Mayer and Feldman, 1967).

In the present study we shall show that, in healthy subjects who are contracting their muscles voluntarily, the late responses become markedly enlarged. The extent of this potentiation has been assessed in different limb muscles and a simple formula devised to express motoneurone excitability. Finally, an analysis will be given of the neural mechanism underlying this changed excitability. In the following paper (Sica, McComas, and Upton, 1971) reduced potentiation is shown to be a characteristic feature of 'upper motoneurone' lesions, even of a very mild nature. Some of this work has already been reported briefly elsewhere (McComas, Sica, and Upton, 1970).

\section{METHODS}

The early experiments were devised independently by A.R.M.U. working at Maida Vale Hospital, and by A.J.M. and R.E.P.S. at the Newcastle Regional Neurological Centre. When each group became aware of the other's work the techniques were standardized as far as possible, so that the results of the two investigations could be combined for presentation.

SUBJECTS A total of 13 men and 10 women, all in good health, volunteered as subjects; their ages ranged from 19 to 49 years. Additional observations were made on older adults who were neurological patients without any evidence of motor involvement. Although the results in these patients will not be reported here, they were similar to those in the control population. Investigations were also performed on two patients in whom certain dorsal roots had been divided for the relief of intractable pain. Patient E.M. was a 45 year old woman in whom persistent pain had resulted from injury to the left knee several years previously; in this patient the L4 and L5 dorsal roots were cut. Patient C.W. was a 54 year old woman who had suffered from pain in her left arm and shoulder after irradiation of the chest for carcinoma of the breast; at operation the C4-T1 dorsal roots were divided.

STIMULATION Two silver electrodes were used for nerve stimulation; they were covered with felt soaked in saline and were spaced $2.5 \mathrm{~cm}$ apart in a Perspex holder. The electrodes were placed on the skin overlying the nerve with the cathode at the point of lowest threshold. In order to study leg muscles (see below) the stimulating electrodes were positioned over the common peroneal nerve at the head of the fibula; for the investigation of hand muscles, the electrodes were situated over the median or ulnar nerves at the wrist. The stimuli were rectangular voltage pulses, either 50 or $200 \mu \mathrm{sec}$ in duration, and were delivered at a rate not greater than one every two seconds. The strengths of stimulation quoted in $\stackrel{\mathbb{D}}{\stackrel{C}{C}}$ the text were those required to excite $\alpha$-motor axons.

RECORDING In each subject one or more of the following muscles were studied: abductor pollicis brevis (APB), 7 abductor digiti minimi (ADM), first dorsal interosseus of the hand (DI), tibialis anterior (TA), and extensor $\stackrel{5}{=}$. digitorum brevis (EDB). Electrical activity in the muscles $\stackrel{0}{\rightleftarrows}$ was examined with surface electrodes. The 'stigmatic'? electrode was a silver cup, $1 \mathrm{~cm}$ in diameter, which had $\Rightarrow$ been filled with electrode jelly and was placed over the $\stackrel{9}{?}$ end-plate zone of the muscle. The reference electrode was 0 a $7 \mathrm{~cm} \times 0.6 \mathrm{~cm}$ strip of silver foil which, in the case of 음 the hand muscles, was wrapped round either the thumb $\overline{\bar{\rho}}$ (for APB), the index finger (for DI), or the little finger $\mathbb{D}$ (for ADM). For TA and EDB muscles the reference electrode was placed away from the muscle belly, either $\infty$ medially or distally. The potentials were fed through an $\vec{\circ}$ amplifier with a frequency response $3 \mathrm{~dB}$ down at $2 \mathrm{~Hz}-$ and $10 \mathrm{kHz}$. They were then displayed on either a $\vec{\omega}$ Hewlett Packard variable persistence storage oscilloscope, $\stackrel{\text { S }}{\text {. }}$ type $141 \mathrm{~A}$, or a Medelec MS5 oscilloscope system. In addition, responses were sometimes averaged using a뭉 Biomac 1000 computer or a Medelec AVM 3/5 unit.

EXPERIMENTAL PROCEDURE The subject lay supine on couch and, after preparing the skin with alcohol a electrode jelly, the stimulating and recording electrod依 0 were attached. The subject was encouraged to relax arf the maximal $M$ wave was elicited by nerve stimulatiof. The stimulus was then made supramaximal by $100 \mathrm{~V}$ and a series of responses was observed. In one type of experiment 10 stimuli were delivered at a rate not exceeding one every three seconds and the peak-to-peak amplituef of each response was measured. In a second type experiment stimuli were given at two-second intervalis and 20 responses were averaged automatically. The. subject was then instructed to contract the muscle under investigation and the appropriate sequence of stimuli was repeated. The contraction was made isometric by the application of external resistance. An attempt was made to make the volitional effect maximal at the moment $\frac{2}{\square}$ when the stimulus was delivered.

FUSIMOTOR BLOCKADE Two experiments were performed $\frac{0}{3}$ on one of the control subjects, a 30 year old male, in whom an attempt had been made to block fusimotor impulse activity by local anaesthesia. The technique followed was similar to that described by Holmes (1963). A $20 \mathrm{ml}$. syringe was filled with $0.5 \%$ lignocaine solution? and the needle of the syringe was inserted into a vein on the back of the hand. After the arm had been raised for two to three minutes to promote venous emptying, a sphygmomanometer cuff round the upper arm was 3 inflated to above the systolic blood-pressure. The anaesthetic was now injected and the cuff remained inflated until the end of the experiment.

\section{RESULTS}

In the initial experiments five muscles were examined $N$ -the abductor pollicis brevis (APB), abductor digiti ${ }_{\omega}^{N}$ 
minimi (ADM), first dorsal interosseus of the hand (DI), extensor digitorum brevis (EDB), and tibialis anterior (TA). When the subject was relaxed and supramaximal nerve stimulation employed, it was possible to record a response in each of these muscles which had the small but variable amplitude characteristic of an F wave (Fig. 1). In any one subject the mean latencies of the $F$ waves in the three muscles of the hand were similar, and in different subjects they ranged from 24 to $32 \mathrm{msec}$; the corresponding values for EDB muscles were rather longer. When a subject contracted any of these muscles the late wave became very much larger. This enhancement is well seen in Fig. 1, which shows responses evoked in an APB muscle. In these superimposed traces the irregularity of the record immediately after the $\mathbf{M}$ wave was probably due to action potentials in thenar muscles innervated by the ulnar nerve. This activity would not have been affected by supramaximal stimuli delivered to the median nerve. These background discharges were less evident in some APB muscles than others-for example, Fig. 5,E-and because of their random nature were largely absent in the averaged records. In studies on muscles other than APB, the collision of antidromic and orthodromic impulses in motor axons effected a complete but temporary suppression of volitional muscle activity after the $M$ wave. The factors responsible for the later part of the 'silent period' have been analysed by many workers (see especially
Merton, 1951); they include 'unloading' of muscle spindles, after-hyperpolarization of motoneurones, and inhibition of motoneurones by Renshaw cells and by polysynaptic inputs from Ib (Golgi tendon organ) fibres.

During voluntary muscular contraction the latency of the enhanced response tended to fluctuate but, in most subjects, the mean value was 2 to $3 \mathrm{msec}$ less than that of the $F$ wave at rest. Figure 1 shows that, in addition to the waves already described, a third evoked potential could usually be recognized during effort; in the hand muscles this last wave had a latency of 48 to $60 \mathrm{msec}$. For convenience we shall refer to the two responses which follow the $M$ wave as the $V_{1}$ and $V_{2}$ (first and second volitional) waves respectively, until their identities have been fully discussed (see below).

$V_{1}$ WAVE Figure 1 shows that the size of the $V_{1}$ wave fluctuated from trial to trial but was usually greater as the contraction became more powerful. In any one subject the $V_{1}$ wave was found to be more prominent in some muscles than in others. In Fig. 2 the amplitudes of $V_{1}$ waves in various muscles have been compared with those of $F$ waves in the same muscles at rest. In this Figure both the $V_{1}$ and $F$ waves have been expressed as fractions of the maximal $\mathbf{M}$ waves recorded in relaxed muscles. There are two advantages in using the $M$ wave as a reference. Firstly, any inconsistency in electrode

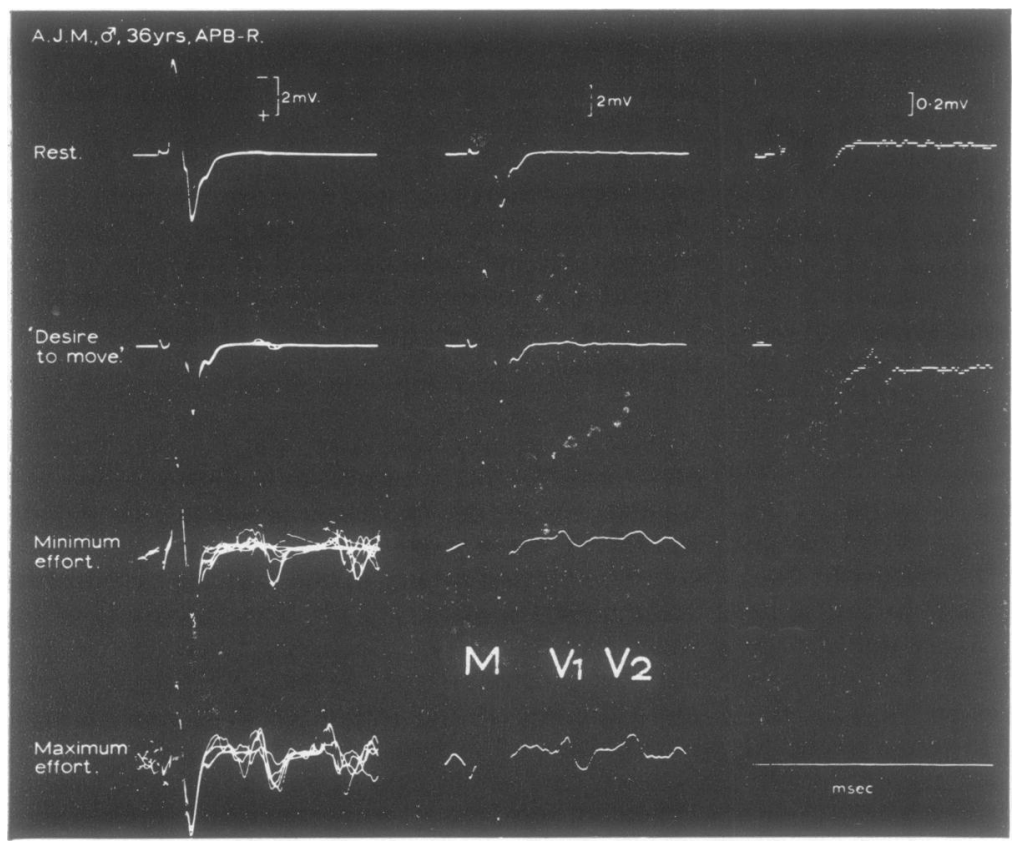

FIG. 1. Late waves recorded in APB muscle of a control subject when resting (top row), 'desiring' to move (second row), and contracting muscle voluntarily (lower two rows). Each record in the left-hand column shows five to 10 superimposed traces, while the middle column contains averaged responses; two of these responses are shown at higher gain in the column on the right. 

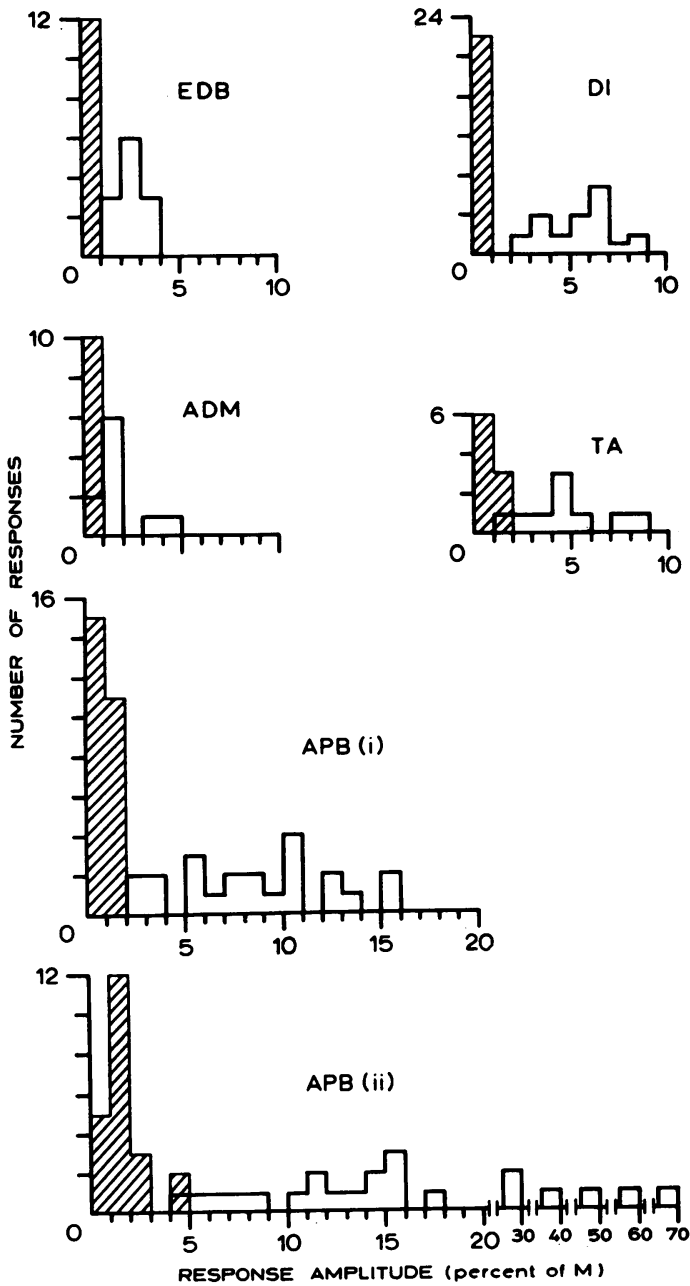

FIG. 2. Amplitudes of $F$ waves during rest (hatched columns) and of $V_{1}$ waves during maximum effort (open columns) in various muscles of control subjects. In the lowest histogram (ABP (ii)) the mean values for each subject were calculated from 10 successive sweeps; in the remaining histograms the responses were averaged automatically (see Methods).

placement will affect both $M$ and $V$ waves to the same extent. Secondly, the $F / M$ and $V_{1} / M$ ratios will indicate the fractions of the motoneurone pool participating in each type of response. In Fig. 2 the differences between the $F$ and $V_{1}$ waves indicate the degrees to which the late waves potentiated during a voluntary contraction. For a given muscle this difference may also be expressed in terms of the $\mathbf{M}$ wave amplitude and is then termed the excitability coefficient, $\mathbf{z}$.

$$
\text { that is, } z=\frac{V_{1}-F}{M}
$$

This coefficient will be considered more fully in $x$ subsequent paper (Sica, McComas, and Upton, 1971).

For all but the histogram at the bottom of Fig. $2 \frac{\mathrm{N}}{\mathrm{N}}$ the mean $F$ and $V_{1}$ potentials were obtained by automatic averaging on an electrophysiological computer (see Methods). This technique did notes take into account the temporal fluctuations of suc= cessive responses. For comparison, the lowest histo-음 gram in Fig. 2 presents the $F / M$ and $V_{1} / M$ ratios which were determined arithmetically, following $\mathbb{D}$ peak-to-peak measurements of potential amplituden on individual traces. Since the variations in response latency did not influence these last results, the values were substantially larger than those obtained by $\vec{\omega}$ electronic averaging.

In Fig. 2 it can be seen that, in all the subjectso examined, the greatest enhancement of the $V_{1}$ wave occurred in APB muscles. The responses in the subject with the largest $V_{1} / M$ ratio $(0 \cdot 69)$ in APBं were of considerable interest, since, on severg occasions, individual $V_{1}$ waves equalled the $M$ waree in size (see Discussion). A further observation $\$$ importance was that, in any one subject, the ampit- tudes of the $V_{1}$ and $F$ waves were similar to thosegint the corresponding muscle of the opposite limb there was no correlation with 'handedness'.

Figure 1 is of interest in another respect, for shows that even the formulation of the 'desire' move was sufficient to induce a $V_{1}$ wave. In this record the completely flat trace before delivery of each stimulus signified that the motoneurones hab not started to discharge.

One other feature of the $V_{1}$ response occurrech with some consistency and deserves mention. It waso found that after a variable number of voluntarye contractions had been executed in the same muscle $\overrightarrow{\overrightarrow{0}}$ it became increasingly difficult to elicit a substantia $B$ $V_{1}$ wave and the mean size of the potentials diminished.

$\mathrm{V}_{2}$ WAVE As already stated, the $\mathrm{V}_{2}$ wave was not present at rest but appeared only during willed cons traction. Although this wave could not be demon strated in some experiments, in most subjects if could be elicited in any of the muscles investigated, being largest usually in APB. The amplitude of this wave, like that of $V_{1}$, fluctuated from trial to triat but was generally larger as the contraction became. more intense. If the responses in successive trials were compared, no consistent relationship emerged between the amplitudes of the $V_{1}$ and $V_{2}$ waves $\tilde{O}$ The latencies of the $V_{2}$ responses also exhibited somet 


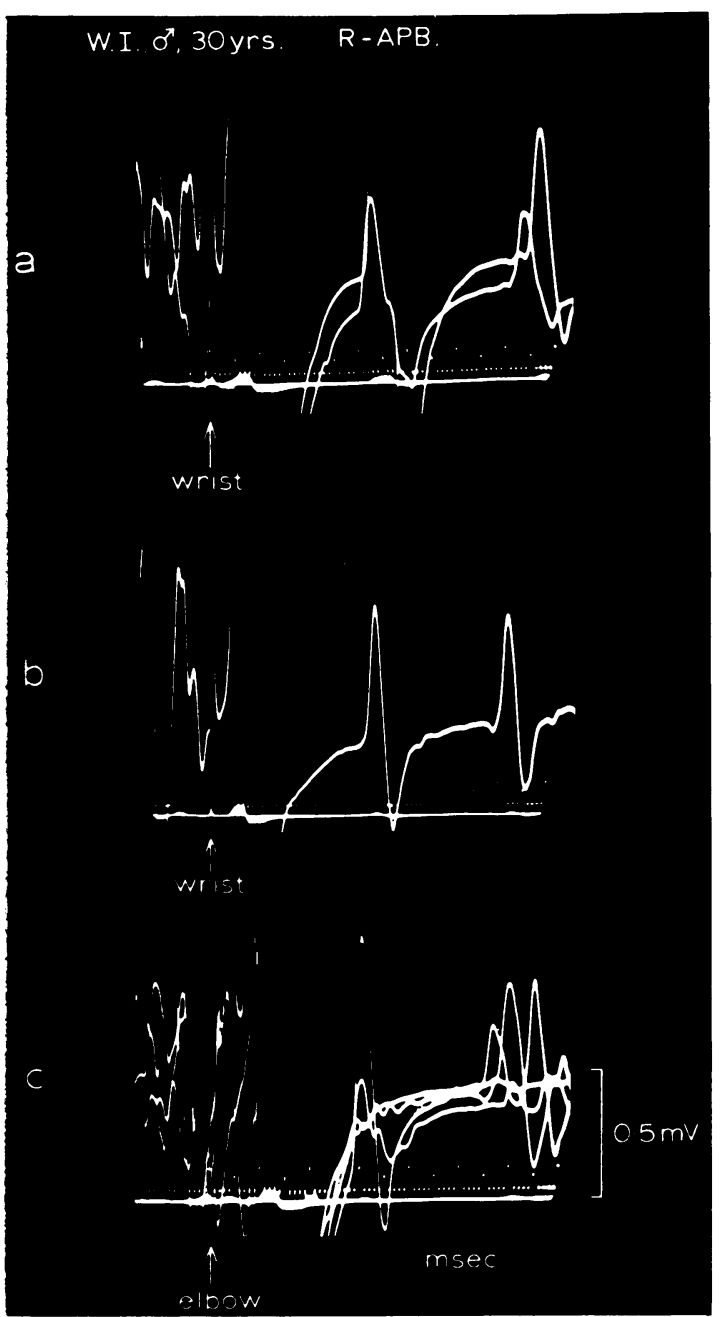

FIG. 3. Effect of site of stimulation on $V_{1}$ and $V_{2}$ waves in $A P B$ muscle of control subject. In record a median nerve was stimulated twice at wrist. $V_{1}$ waves had latencies of 30 and $31 \mathrm{msec}$, while those of $V_{2}$ responses were 60 and $61 \mathrm{msec}$. Record b shows the earliest $V_{2}$ wave (latency $57 \mathrm{msec}$ ) observed in a further 10 trials; $V_{1}$ latency 32 msec. Record c shows four superimposed traces of responses after stimulation of median nerve at elbow; $V_{1}$ and $V_{2}$ latencies ranged from $27-29 \mathrm{msec}$ and $52-60 \mathrm{msec}$ respectively. Times of stimulation shown by arrows. Distance between cathodal stimulating electrodes at wrist and elbow was $28 \mathrm{~cm}$.

scatter but in all the muscles tested, whether of the arm or the leg, the mean latency was approximately $25 \mathrm{msec}$ longer than that of the corresponding $V_{1}$ wave. With repeated stimulation, however, the

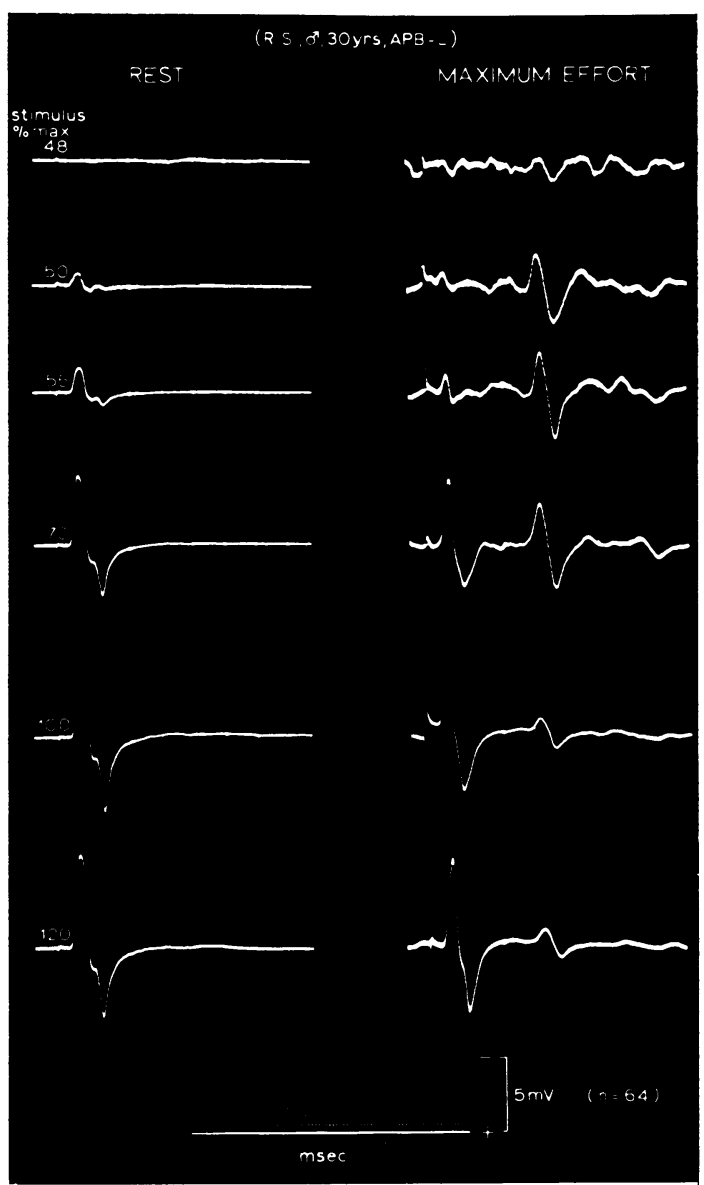

FIG. 4. Effect of stimulus intensity on potentiated late waves in control subject; intensities have been expressed as percentages of those requirod to evoke a maximum $M$ wave. Each record shows the average of 64 trials. The $V_{2}$ response was only evident when $70 \mathrm{~V}$, or weaker, stimuli were used. Towards the end of the experiment, when larger stimuli were being used, the response failed to appear.

amplitude of the third wave tended to decline while the latency increased. Not infrequently the wave eventually disappeared entirely-for example, Figs. 4 and 5).

FURTHER EXPERIMENTS DESIGNED TO DEMONSTRATE NATURE OF $v_{1}$ AND $v_{2}$ WAVES Site of stimulation In order to analyse the neural mechanisms responsible for the $V_{1}$ and $V_{2}$ waves certain additional observations w:re made, the significance of which is considered below (see Discussion). In the first procedure the point of nerve stimulation was moved 
proximally. Thus, while APB was being contracted voluntarily, the median nerve was stimulated at the elbow instead of the wrist. $V_{1}$ and $V_{2}$ waves were both present and in each case the latency was observed to shorten by several milliseconds (Fig. 3). This reduction served to distinguish these potentials from that resulting from spindle-mediated excitation of $\alpha$-motoneurones ('S' response). Thorne (1965) reported that the latency of this last response was 10 to $15 \mathrm{msec}$ greater than that of the $F$ wave. According to our own data the $S$ response should have occurred in between the $V_{1}$ and $V_{2}$ waves.

Stimulus intensity When the stimulus strength was reduced from a value which was supramaximal for the $\mathbf{M}$ wave to one which was just above threshold, a potentiated late wave could still be observed (Fig. 4). Since, in these circumstances, the late response was larger than the $\mathrm{M}$ wave, it clearly must have been of reflex origin. Furthermore, it can be seen that as the stimulus strength was increased the late wave diminished while the $M$ wave grew larger. This behaviour served to identify the late wave as an $\mathrm{H}$-reflex. In Fig. $5(\mathrm{H}, \mathrm{I})$ it can be seen that the potentiation of the H-reflex still occurred after local anaesthesia (see below).

Local anaesthesia In another type of study the effects of local anaesthesia on the responses evoked by supramaximal nerve stimulation were investigated on two separate occasions in subject R.S. In this subject the $V_{2}$ wave could not be detected before anaesthesia and hence the observations were limited $\stackrel{\mathbb{D}}{\subseteq}$ to the $V_{1}$ response. From Fig. $5(D, E, F)$ it can be seen that sufficient anaesthetic had been injected intravenously in the ischaemic arm to cause some reduction in the $\mathbf{M}$ wave (see Methods). It wase therefore judged that impulse conduction in fibres? smaller than the $\alpha$-motor axons, such as the fusimotor axons, would have been completely blocked. In both experimenis on this subject it was found that a $V_{1}$ wave of good amplitude could still be recorded $\stackrel{\text { क }}{9}$ during effort (Fig. 5, E,F).

Dorsal root section Two patients were studied in whom certain dorsal roots had been divided for theo relief of intractable pain (see Methods). In patient E.M. both tibialis anterior muscles were investigated $\overrightarrow{0}$ six days after section of the L4 and L5 dorsal roots: on the left side. Figure 6 shows that on the affected $\vec{\omega}$ side there was no late response during relaxation oro during voluntary exertion. On the normal side, $\overline{5}$ however, the small $F$ wave was replaced by a substantial $V_{1}$ wave during effort; the automatically $\$$ analysed $V_{1} / M$ ratio was 0.31 (see also Fig. 2). On.ं neither side could a $\mathrm{V}_{2}$ wave be demonstrated.

In patient C.W. the left APB muscle was examinged seven days after the C4-T1 dorsal roots had been $\mathrm{q}_{\mathrm{O}} \mathrm{t}_{-}^{\circ}$ on the same side. Figure 6 shows that, during effora, the $V_{1}$ response occurred only once on the 10 supqimposed traces and was identical in all respects wigh the $F$ wave evoked in the relaxed muscle. The unit nature of this potential suggested that a single mor unit was involved. Figure 6 also shows that on onecte

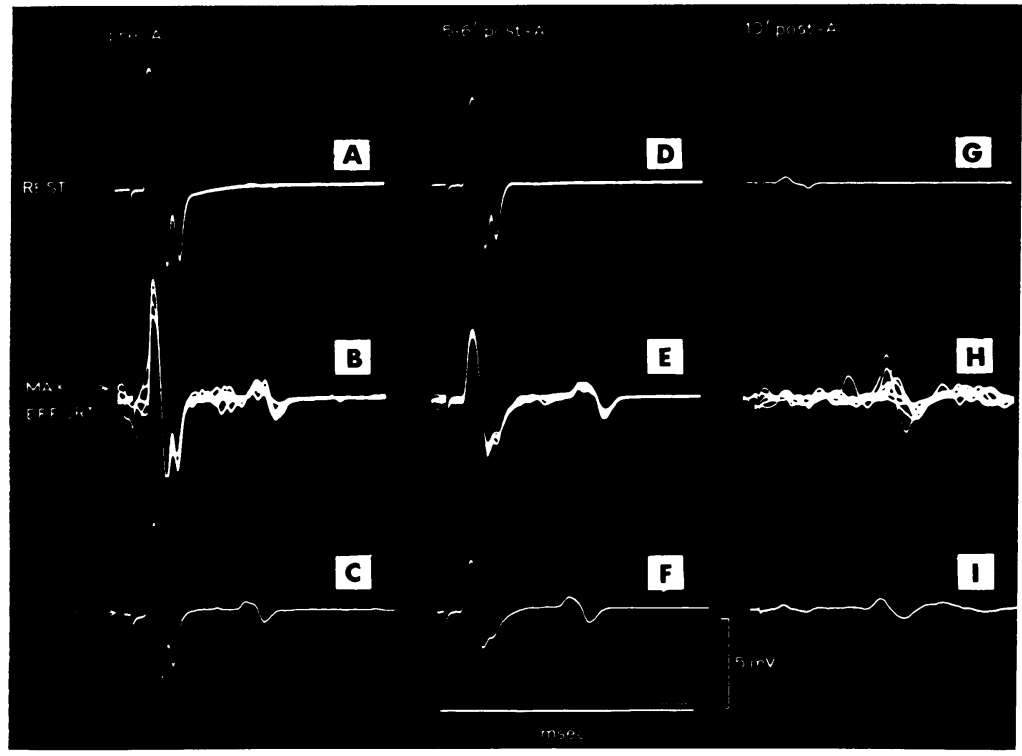

FIG. 5. Potentiation of late waves in $A P B$ muscle before and after local anaesthetic has been given to block fusimotor activity. In ABDEGH, 5-10 traces have been superimposed in each record; CFI show automaticallydetermined averages, each of 10 trials. The stimuli were either supramaximal for motor axons (A-F) or submaximal (G-1). Times after injection are indicated at the top of the Figure. 


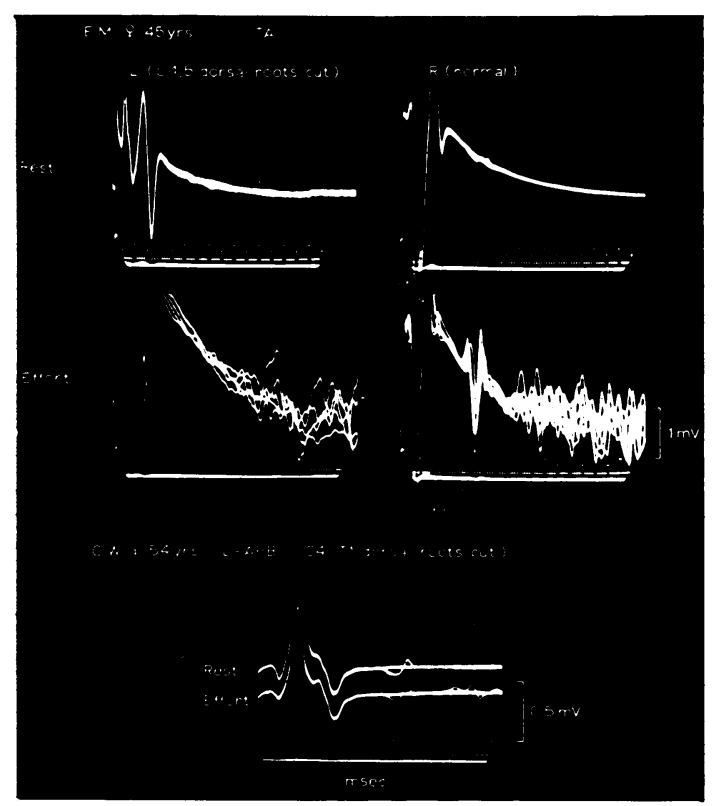

FIG. 6. Potentiation studies in two patients who had previously undergone dorsal rhizotomy. See text. In the lowest pair of traces the stimuli were delivered at the start of the sweep.

occasion a third response appeared in the contracting muscle. This last potential was tentatively diagnosed as a small $\mathrm{V}_{2}$ wave even though the latency, $38 \mathrm{msec}$, was rather shorter than that usually enc suntered for this response.

\section{DISCUSSION}

It is known from the work of Hagbarth (1962) that there is potentiation of the $\mathrm{H}$ reflex during voluntary contraction. However, neither this author nor Mayer and Feldman (1967) found any evidence of late wave enhancement if supramaximal, as opposed to submaximal, nerve stimulation was employed. In the present study such potentiation has been clearly shown and, in addition, it has been possible to demonstrate the appearance of a third wave during voluntary contraction. The nature of these two waves will now be considered.

$\mathrm{V}_{1}$ WAVE It could be shown that the spinal cord was involved in the production of the $\mathrm{V}_{1}$ wave by the observation that, when the stimulating electrodes were moved proximally, the latency declined. Several possible mechanisms for this wave deserve consideration. The first possibility is that the descending motor pathways excite the motoneurones after the antidromic impulses, initiated by the stimuli, have died away (Fig. 7 (a), (b) ). Since the dissipation of the antidromic impulses would take place simultaneously throughout the motoneurone pool, much of the ensuing volitional activity in these cells would also occur synchronously and would cause a definite wave in the muscle record. The second possibility is that, due to the background facilitation of motoneurones effected by descending motor pathways, there is enhancement of the small recurrent discharge which usually follows the antidromic impulse -that is, the F wave (Fig. 7 (c) ). It can be seen that, since neither mechanism requires the presence of the dorsal roots, the $V_{1}$ waves should still have been present in the patients who had undergone posterior rhizotomy. The fact that the waves were abolished clearly indicates that neither mechanism was important and that the $\mathrm{V}_{1}$ wave, because of its dependence on the dorsal roots, had a reflex origin.

Could the $\mathrm{V}_{1}$ wave have been due to 'unmasking" of H-reflex discharges? It is conceivable that, in motoneurones such as those supplying the small muscles of the hand, H-reflex discharges are normally elicited by sensory inputs in relaxed subjects but prevented, by collision with antidromic impulses ('A-H' collision), from reaching muscles and being detected (Fig. 7 (d) ). During a voluntary contraction the antidromic volley would be abolished in some of the motor axons by collisions with volitional (a)

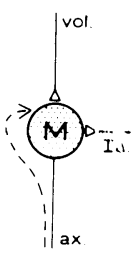

(d)

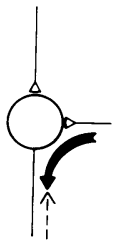

(b)

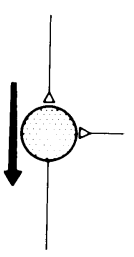

(e)

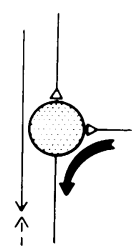

(c)

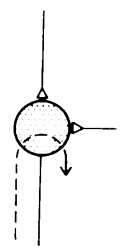

(f)

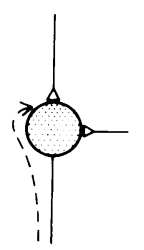

(g)

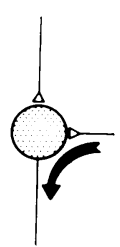

FIG. 7. Possible mechanisms underlying gonesis of $V_{1}$ wave. $M$ is motoneurone soma, stippling indicates excitation by descending pathways (vol); ax, motoneurone axon. Passage of orthodromic and antidromic impulses shown by bold and interrupted lines respectively. See text. 
impulses; these axons would be 'cleared' for transmission of H-reflex impulses out to the muscle (Fig. 7 (e) ). This 'unmasking' hypothesis supposes that motor axons have lower thresholds to stimuli than Ia fibres. However, if this were so, then it would not be possible to record $\mathrm{H}$-reflexes from these muscles in any circumstances. Yet $\mathrm{H}$-reflexes can be observed in infancy (Thomas and Lambert, 1960) and, more significantly, in adults with upper motoneurone lesions (Teasdall, Park, Languth, and Magladery, 1952). In the present study the results of experiments employing submaximal stimuli were also relevant, for they showed that $\mathrm{H}$-reflexes appeared during maximal voluntary contraction (see also Hagbarth, 1962). These three observations suggest that the real reason for the normal absence of $\mathrm{H}$-reflexes in certain muscles is a lack of adequate facilitation of motoneurones. Expressed in terms of membrane theory, the results suggest that the excitatory postsynaptic potentials (EPSPs) induced by the Ia fibre inputs are not sufficiently large to depolarize the motoneurone membrane to the firing level, and that additional EPSPs from other sources are required before an impulse can be initiated. In the calf muscles the presence of $\mathrm{H}$-reflexes in the resting leg would suggest that either the EPSPs from Ia fibres are relatively powerful or that background excitation is high, or both. The persistence of $\mathrm{H}$ reflexes in calf muscles during the flaccid paralysis immediately following upper motoneurone lesions (Weaver, Landau, and Higgins, 1963) suggests that the efficacy of the Ia inputs is the main factor.

Even though A-H collisions do not occur in the resting state, it is clear from the present experiments that they are an important feature of motoneurones participating in voluntary contractions. Figure 4 shows that, when stimuli are increased from threshold to a supramaximal strength, the $V_{1}$ wave at first enlarges, and then, as the $M$ wave grows, the $V_{1}$ wave declines. This behaviour of the $V_{1}$ wave is entirely similar to that of the H-reflex in the calf muscles of a relaxed subject. It seems reasonably certain that the decline in the $V_{1}$ wave, like that of the H-reflex, is brought about by collisions between the reflex and antidromic discharges in motor axons. The reason why the potentiated part of the $V_{1}$ wave is not completely abolished by supramaximal stimulation depends on another type of collision in motor axons, this time between antidromic and 'volitional' impulses (A-V collisions). Figure 7 (e) shows that every time such a collision occurs the corresponding motor axon is 'cleared' for transmission of an Hreflex impulse down to the muscle. In the Appendix to this paper a method is described for calculating the theoretical size of the $V_{1}$ wave during any degree of voluntary effort; a method is also given for deter- mining the fraction of the motoneurone pool parti- $-\stackrel{\mathbb{D}}{=}$ cipating in the H-reflex.

In the control subject who displayed the largest $\mathrm{V}_{\mathbf{1}} / \mathrm{M}$ ratio for APB (0.69; see Fig. 2), there were several occasions when the $V_{1}$ response matchedon the $M$ wave in amplitude. This finding indicated that not only were all the APB motoneurones exciteda. reflexly, but that in most cells the EPSPs induced by $\vec{乛}$ the Ia inputs were sufficiently pronounced for 'late' $\Rightarrow$ impulses to be fired. In some cells these impulses? would have been initiated after the antidromic volleye had died away (Fig. 7 (f),(g) ). In other cells, presumably the majority, the late impulses would follows collision between the antidromic volley and an earlier reflex discharge. It has recently been sug gested that the Ia fibres activate motoneurones by a polysynaptic, as well as a monosynaptic route_ (Tsukahara and Ohye, 1964); these longer pathways might be especially important in the initiation of late? impulses.

In an earlier paper (McComas et al., 1970) the (first) potentiated late response was referred to as anp F wave, since supramaximal stimuli were beingo employed and it had not been possible to analyseeg the underlying neural mechanism. However, ofiro more recent results, discussed above, make it clest that this wave is composed almost entirely of potentiated $\mathrm{H}$-reflex. The relevance of this findige to motoneurone physiology is considerable. Th@s, during a voluntary contraction the motoneuro are being excited repeatedly by descending moखr pathways. However, it is quite conceivable thatco during such a contraction the availability of moto-neurones to reflex inputs could be restricted by pre synaptic inhibitory mechanisms. Thus it is knowne that electrical stimulation of the medial reticulars formation in the cat induces presynaptic inhibition of Ia fibres (Carpenter, Engberg, and Lundberg 1966). It is therefore important to establish whether descending fibres from this structure, or otherso exercising similar effects, are activated when the ${ }^{3}$ motor cortex organizes a voluntary movement Viewed in this light, the significance of the $V_{1}$ wave. is apparent. This response clearly shows that the Iasinputs continue to have ready access to the moto? neurones and, furthermore, that they exert a much? larger effect due to the background facilitation of motoneurones imposed by the descending motoro pathways. Additional evidence, which would be compatible with these conclusions, has come froms the 'unloading' experiments of Angel, Eppler, and Iannone (1965) and other observations on the silen? period (Merton, 1951). Our findings on subjectș who had conceived the desire to move, but who were not actually contracting their muscles, were of somes interest, since they also revealed enhanced back ${ }_{\tilde{W}}^{N}$ 
ground facilitation of motoneurones. A more detailed study of these changes in excitability during the prelude to voluntary movement has been made by Requin (1967; see also Gottlieb, Agarwal, and Stark, 1970). The relatively large potentiation of the responses in APB, compared with other muscles, was a consistent finding in all subjects and also deserved consideration. It is tempting to suppose that this inequality was in some way related to the importance of the thumb in skilled motor tasks and to the large cortical area representing movements of this digit.

How do the descending motor pathways bring about the facilitation of motoneurones which we have demonstrated by our present techniques? Two possible mechanisms exist. Firstly, the descending fibres could employ a relatively direct route so as to excite the motoneurones monosynaptically or via neighbouring interneurones. The second possibility is that the descending fibres activate the motoneurones indirectly by terminating on fusimotor neurones and then exerting facilitation through the stretch reflex loop (Merton, 1953). We have analysed this situation by seeing if potentiation could occur after activity in the stretch reflex loop had been reduced by anaesthetic blockade of fusimotor fibres. The fact that marked potentiation could still take place, while not excluding an influence by the indirect pathway, served to emphasize the powerful nature of the direct route.

$V_{2}$ WAVE The origin of the $V_{2}$ wave was difficult to define for the extremely labile nature of this wave in normal subjects made hazardous the interpretation of the findings in the two patients with sectioned dorsal roots. Although in patient E.M. the wave was absent on the treated side, it could not be detected on the normal side either; in patient C.W. the wave was barely present. One obvious explanation would be that this wave, like the $V_{1}$ response, was a reflex. Many possibilities for such a reflex exist, since, in the present study, the electrical stimuli would have (a)

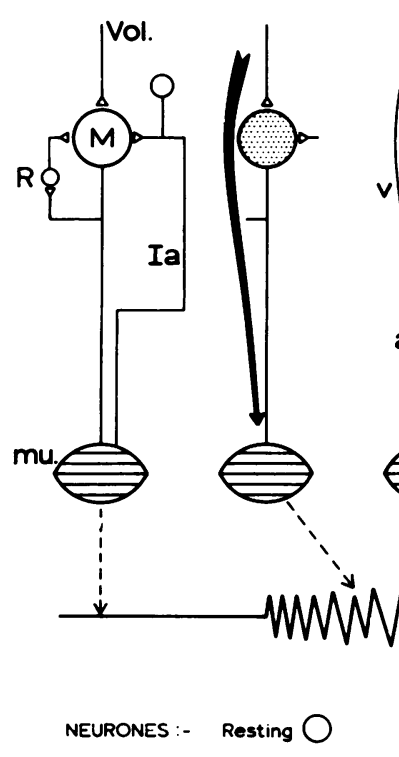

(c)

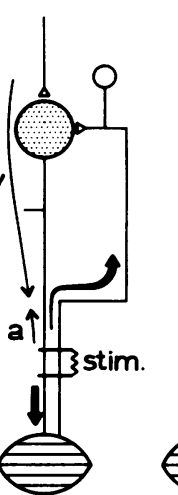

(d)

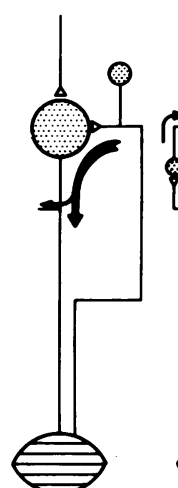

(e)

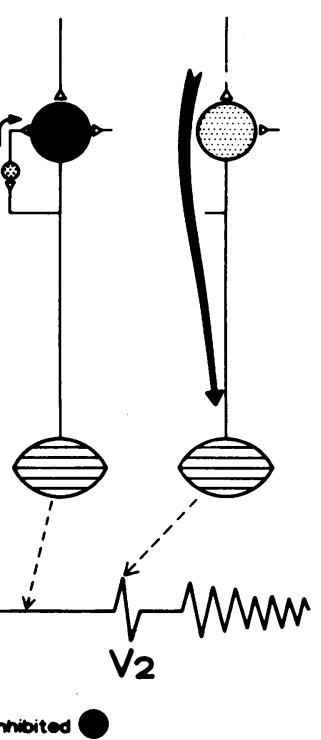

(f)

FIG. 8. Postulated neural mechanisms responsible for $V_{1}$ and $V_{2}$ waves; (a) antidromic impulses; $\mathbf{M}$, motoneurone soma; $\mathrm{mu}$, muscle; $\mathbf{R}$, Renshaw cell; stim., stimulating electrodes; v, volitional impulses. Initially muscle is at rest (a) but then undergoes voluntary contraction (b). In (c) the muscle nerve is stimulated so as to fire an $M$ wave, an antidromic volley, $\mathrm{a}$, and volleys in Ia and Ib fibres. Some of the motor axons are 'cleared' of antidromic activity by collisions with volitional impulses. In (d) the H-reflex discharge occurs $\left(V_{1}\right.$ wave $)$ and is succeeded by postsynaptic inhibition of motoneurone from Renshaw cells and Ib fibres (e). In (f) a reduction in inhibition allows descending volitional, or polysynaptic reflex inputs, to excite motoneurone ( $V_{2}$ wave). See text. 
evoked volleys in cutaneous and joint-receptor fibres, as well as in axons from muscle and tendon receptors. The late onset of the wave could hardly be accounted for by slowed conduction in sensory fibres, since there was only a relatively small difference in latency when the site of nerve stimulation was moved from the wrist to the elbow (Fig. 3). If the $V_{2}$ wave were a reflex, then it seems more likely that the late onset reflected polysynaptic transmission or conduction over long distances in the spinal cord. It is doubtful if a long-loop reflex involving the brain-stem (Gernandt and Shimamura, 1961) could have been involved, since the intervals between the $V_{1}$ and $V_{2}$ waves should have been longer for muscles of the foot than those of the hand; our studies show that this was not the case.

A second explanation is that the $\mathrm{V}_{2}$ wave signalled the period of heightened excitability which neurones display after the termination of an inhibitory postsynaptic potential (IPSP: see Andersen and Sears, 1964). In this case an IPSP would have been imposed by Renshaw cells which were themselves excited by either ortho- or antidromic impulses in motor axons. Disynaptic inhibition from Ib inputs and post-spike hyperpolarization would also contribute to the rise in membrane potential. During the succeeding phase of increased excitability the motoneurone would be able to respond to inputs from descending motor pathways. Figure 8 summarizes much of the preceding discussion by showing the mechanisms tentatively suggested for the genesis of the $V_{1}$ and $V_{2}$ waves in relation to the electromyogram. It is hoped that the situation regarding the $V_{2}$ wave will ultimately be clarified by further observations in patients with divided dorsal roots.

In conclusion, it would appear from our work that the potentiated part of the $V_{1}$ wave and possibly the $\mathrm{V}_{2}$ wave reflect the operation of relatively simple spinal mechanisms which require a certain amount of descending facilitation to become demonstrable. We have already drawn attention to the labile nature of these responses, even if the intensity of voluntary contraction is kept maximal and the strength of stimulation carefully controlled. In a subsequent paper (Sica et al., 1971) we shall show that even a very small change in background excitation may be sufficient to prevent normal potentiation of the $V_{1}$ response. As a consequence it has been possible to use the potentiated $V_{1}$ response as a sensitive test of 'upper motoneurone' function in neurological disorders.

We are grateful to Mr. J. Hankinson for permission to study his patients and to Dr. F. Petito for help with some of the later experiments. In addition we wish to thank Mr. T. Blogg, Mr. J. Smith, and Mr. C. Wallace for technical services and Mrs. Y. Chisholm for secretarial assistance. Financial support was received from the Muscular Dystrophy Group of Great Britain, the Muscular Dystrophy Associations of America, Inc., and the Medical Research Council. One of us (R.E.P.S.) hel\$ a British Council Scholarship.

\section{REFERENCES}

Andersen, P., and Sears, T. A. (1964). The role of inhibitio in the phasing of spontaneous thalamo-cortical discharge. J. Physiol. (Lond.), 173, 459-480.

Angel, R. W., Eppler, W., and Iannone, A. (1965). Silence period produced by unloading of muscle during voluntary contraction. J. Physiol. (Lond.), 180, 864-870.

Carpenter, D., Engberg, I., and Lundberg, A. (1966). Primar afferent depolarization evoked from the brain stem anc cerebellum. Arch. ital. Biol., 104, 73-85.

Dawson, G. D., and Merton, P. A. (1956). 'Recurrent' dis charges from motoneurones. XXth International Physio ${ }^{\infty}$ logical Congress, Brussels, 1956. Abstracts of Communica $\overrightarrow{0}$ tions, pp. 221-222.

Gassel, M. M., and Wiesendanger, M. (1965). Recurrent and reflex discharges in plantar muscles of the cat. Actक physiol. scand., 65, 138-142.

Gernandt, B. E., and Shimamura, M. (1961). Mechanisms of̦ interlimb reflexes in cat. $J$. Neurophysiol., 24, 665-676.

Gottlieb, G. L., Agarwal, G. C., and Stark, L. (1970). Inter $\underset{ \pm}{\omega}$ actions between voluntary and postural mechanisms in the் human motor system. J. Neurophysiol., 33, 365-381.

Hagbarth, K.-E. (1962). Post-tetanic potentiation of myot reflexes in man. J. Neurol. Neurosurg. Psychiat., 25, 1 त्tत0

Hoffmann, P. (1918). Über die Beziehungen der Sehnend reflexe zur willkürlichen Bewegung und zum Torfs.Z. Biol., 68, 351-370.

Holmes, C. McK. (1963). Intravenous regional analgesta A useful method of producing analgesia of the $\lim 8 s \frac{\mathbb{D}}{7}$ Lancet, 1, 245-247.

Lloyd, D. P. C. (1943). Neuron patterns controlling trąṣ@ mission of ipsilateral hind limb reflexes in cat. $J$. Nef physiol., 6, 293-315.

Magladery, J. W., and McDougall, D. B. Jr. (1959). Electro physiological studies of nerve and reflex activity in norma man. I. Identification of certain reflexes in the electroo myogram and the conduction velocity of peripheral nerve fibres. Bull. Johns Hopk. Hosp., 86, 265-290.

Magladery, J. W., Porter, W. E., Park, A. M., and Teasdall@ R. D. (1951). Electrophysiological studies of nerve ang reflex activity in normal man. IV. The two-neurone reflex and identification of certain action potentials from spinat roots and cord. Bull. Johns Hopk. Hosp., 88, 499-519.

Mayer, R. F., and Feldman, R. G. (1967). Observations on the nature of the $\mathrm{F}$ wave in man. Neurology (Minneap.) $17,147-156$.

McComas, A. J., Sica, R. E. P., and Upton, A. R. M. (1970) Excitability of human motoneurones during effort. $J$ Physiol. (Lond.), 210, 145-146P.

McLeod, J. G., and Wray, S. H. (1966). An experimentaDi study of the $\mathrm{F}$ wave in the baboon. J. Neurol. Neurosurg? Psychiat., 29, 196-200.

Merton, P. A. (1951). The silent period in a muscle of the human hand. J. Physiol. (Lond.), 114, 183-198.

Merton, P. A. (1953). Speculations on the servo-control of movement. In The Spinal Cord, Ciba Symposium, pp. 247 260. Churchill: London.

Merton, P. A. (1954). Voluntary strength and fatigue. $J$ Physiol. (Lond.), 123, 553-564.

Requin, J. (1967). Organisation de l'activité motrice prépara toire. Premiers resultats obtenus chez l'homme dans uno situation de temps de reaction. In Hommage à André Rey pp. 337-366, ed. Dessart, C. Solédi:Liège. 
R znshaw, B. (1941). Influence of discharge of motoneurons upon excitation of neighbouring motoneurons. J. Neurophysiol., 4, 167-183.

Siza, R. E. P., McComas, A. J., and Upton, A. R. M. (1971). Impaired potentiation of $\mathrm{H}$-reflexes in patients with upper motoneurone lesions. J. Neurol. Neurosurg. Psychiat., 34, 712-717.

Teasdall, R. D., Park, A. M., Languth, H. W., and Magladery, J. W. (1952). Electrophysiological studies of reflex activity in patients with lesions of the nervous system. II. Disclosure of normally suppressed monosynaptic reflex discharge of spinal motoneurones by lesions of lower brain-stem and spinal cord. Bull. Johns Hopk. Hosp., 91, 245-256.

Thomas, J. E., and Lambert, E. H. (1960). Ulnar nerve conduction velocity and $\mathrm{H}$-reflex in infants and children. J. appl. Physiol., 15, 1-9.

Thorne, J. (1965). Central responses to electrical activation of the peripheral nerves supplying the intrinsic hand muscles. J. Neurol. Neurosurg. Psychiat., 28, 482-495.

Tsukahara, N., and Ohye, C. (1964). Polysynaptic activation of extensor motorneurones from group Ia fibres in the cat spinal cord. Experientia (Basel), 20, 628-629.

Weaver, R. A., Landau, W. M., and Higgins, J. F. (1963). Fusimotor function. Part II. Evidence of fusimotor depression in human spinal shock. Arch. Neurol. (Chic.), 9, 127-132.

\section{APPENDIX}

PREDICTED SIZE OF THE $\mathrm{V}_{1}$ WAVE From theoretical considerations it is possible to calculate the size of the $V_{1}$ wave which would be expected during any degree of voluntary effort.

$$
\text { that is, } \mathrm{V}_{1}=\mathrm{M}\left(\frac{\mathrm{H}_{\mathrm{E}} \mathrm{H}_{\mathrm{V} f t}}{1000}+\mathrm{H}_{\mathrm{L}}+\mathrm{A}\right) \ldots \text { (i) }
$$

where $M=$ maximum amplitude of $\mathbf{M}$ wave in resting muscle.

$\mathrm{H}_{\mathrm{E}}=$ proportion of motoneurone pool discharging 'early' H-reflex impulses.

$\mathrm{H}_{\mathrm{L}}=$ proportion of motoneurone pool generating 'late' H-reflex impulses-that is, after antidromic impulses have died away.

$\mathbf{H}_{\mathbf{V}}=$ proportion of $\mathbf{H}_{\mathbf{E}}$ motoneurones participating in voluntary contraction.

f $=$ frequency of discharges in $\mathrm{H}_{\mathrm{V}}$ neurones during voluntary activation (impulses/sec).

t = time for impulse to travel between cord and stimulating electrodes (msec).

A $=$ proportion of motoneurones firing recurrent impulses after antidromic invasion.

It will be noted that the equation does not contain a term for the refractory period of the motor nerve axon. On the one hand, the refractory period will temporarily prevent the initiation of an antidromic volley after the passage of volitional impulses past the stimulating electrodes. The effect will be the same as an increase in $t$. On the other hand, the refractory period after the discharge of a 'volitional' impulse in the axon hillock will similarly curtail the time available for reflex transmission. This time the effect will be as if $t$ is reduced. Since the two effects of the refractory period are antagonistic this factor can be ignored.

The magnitude of some of the terms in the equation can be determined from the data available. For example, on the basis of the $V_{1}$ waves in patients with cut dorsal roots (Fig. 6), $\mathrm{A}$ is not likely to be very large. There is no way of estimating $\mathrm{H}_{\mathrm{L}}$, though it will probably exceed the value of $V_{1}$ when the patient is about to move (Fig. 1). The firing frequencies of motoneurones, $f$, have been the subject of many investigations (for current views see Das Gupta and Simpson, 1962; Clamann, 1970). In the case of motoneurones innervating small muscles of the hand, Bigland and Lippold (1954) found that the range of frequencies did not usually exceed 10 to 40 impulses/sec; rates higher than $50 / \mathrm{sec}$ were never seen. The time taken for impulse conduction, $t$, may be readily determined from the latency of the $\mathbf{H}$ reflex, ignoring synaptic delay and assuming that the velocities of impulse conduction are similar in motor and sensory fibres.

that is, $\mathrm{L}_{\mathrm{H}}=2 t+\mathrm{L}_{\mathrm{M}}$

where $L_{H}$ and $L_{M}$ are the latencies of the H-reflex and $M$ wave respectively. Let us now consider the situation in subject R.S. during a maximum contraction (Fig. 4). $\mathrm{H}_{\mathrm{V}}$ will be unity (cf. Merton, 1954) and a reasonable value for $f$ would be 20 (impulses/ sec). $L_{H}$ and $L_{M}$ are 28 and $3 \mathrm{msec}$ respectively, so that, from equation (ii), $t$ will be $12.5 \mathrm{msec}$. If the terms $H_{L}$ and $A$ are ignored, then from equation (i),

$$
\mathrm{V}_{1}=\frac{\mathrm{M} \times \mathrm{H}_{\mathrm{E}} \times 1 \times 20 \times 12.5}{1000}
$$$$
\text { and } \quad H_{E}=4.0 \times \frac{V_{1}}{M}
$$

where $\mathrm{H}_{\mathrm{E}}$ is the proportion of the motoneurone pool excited 'early' by the Ia afferents. In the example depicted in Fig. 4, $V_{1}$ and the resting $M$ wave were 2.0 and $11.0 \mathrm{mV}$ respectively. Hence $\mathrm{H}_{\mathrm{E}}$ would be about $73 \%$ of the motoneurone pool. From the data available in this Figure it is also possible to obtain a rough estimate of $H_{E}$ by comparison of $M$ and $H$ wave amplitudes after submaximal stimulation (see below).

DETERMINATION OF FRACTION OF MOTONEURONE POOL EXCITED REFLEXLY Táboříková and Sax (1968) describe two methods for estimating the fraction of the motoneurone pool contributing to an $\mathrm{H}$-reflex. One of their methods, depending on the refrc ct ory periods of axons, is not applicable to the experimental situation in the present study where motor axons are conducting volitional, as well as reflex, impulses. The technique which will now be de- 


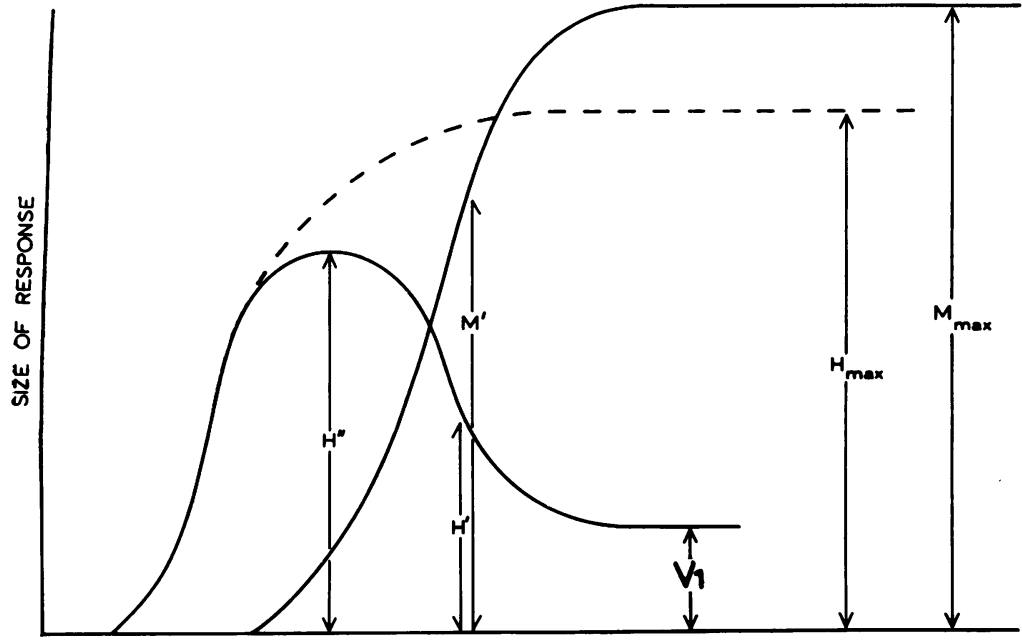

FIG. 9. Relationship between stimulus strength and sizes of $M$ waves and $H$-reflexes at different stimulus strengths. Interrupted line shows size of $H$-reflex which would be recorded if no collisions took place between reflex and antidromic impulses. See text.

STIMULUS STRENGTH

scribed is a variation of the one considered by Táborríková and Sax in the Discussion of their paper. These authors assume, as we do here, that there is no correlation between the reflex excitability of a motoneurone and the threshold of its axon to percutaneous electrical stimulation. They also ignore, as we do, those H-reflex impulses which are fired too late to collide with the antidromic volley and those impulses generated by a recurrent mechanism - that is, the $H_{L}$ and $A$ fractions in our equation (i) of the preceding paper.

Consider now a relaxed muscle and suppose that a large but submaximal stimulus is given to the nerve so as to excite an $\mathrm{H}$-reflex wave together with substantial $M$ wave $\left(\mathrm{H}^{\prime}\right.$ and $\mathbf{M}^{\prime}$ in Fig. 9). Let the size of the maximal $\mathbf{M}$ wave be $\mathbf{M}_{\max }$ and let $\mathbf{H}_{\max }$ denote the largest $\mathrm{H}$ reflex which would be recorded if there were no collisions. In practice, it will be possible to look for $\mathrm{H}$ reflexes only in those motor units of which the axons have not been excited directly-that is, $\mathbf{M}_{\max }-\mathbf{M}^{\prime}$. Thus, although some of the $\mathbf{M}^{\prime}$ axons will be conducting $\mathrm{H}$-reflex impulses, the latter will not reach the muscle because of collision with the antidromic volley. Hence the proportion of motoneurones discharging reflexly,

$$
\mathbf{P} \text {, will be } \frac{\mathbf{H}^{\prime}}{\mathbf{M}_{\max }-\mathbf{M}^{\prime}}
$$

When the muscle undergoes voluntary contraction the analytical situation becomes more complicated due to collision between antidromic and volitional impulses in motor axons. These 'A-V' collisions will 'clear' the axons so that H-reflex discharges can reach the muscle and cause a $V_{1}$ wave (cf. Figs. 7, 84. The incidence of motoneurones firing volition 10 impulses during the passage of the antidromic volligy will be equal to

$\mathrm{V}_{1}$ (measured after a supramaximal stimulus) $\mathbf{H}_{\max }$ (to be determined) Accordingly the fraction of the motoneurone pos! able to contribute to the recorded $\mathrm{H}$-reflex will $\overline{\mathrm{B}} \overrightarrow{\mathrm{Q}}$ rather larger than $\mathbf{M}_{\max }-\mathbf{M}^{\prime}$; it will $M_{\max }-M^{\prime} \frac{\left(H_{\max }-V_{1}\right)}{H_{\max }}$. If $H^{\prime \prime}$, the largest $H$ reflex observed, is used as an approximation of $\mathbf{H}_{\max }$, then equation (i) becomes:

$$
\mathbf{P}=\frac{\mathbf{H}^{\prime}}{\mathbf{M}_{\max }-\mathbf{M}^{\prime} \frac{\left(\mathbf{H}^{\prime \prime}-\mathbf{V}_{\mathbf{1}}\right)}{\mathbf{H}^{\prime \prime}}}
$$

As an example of the application of this techniqueo the data in Fig. 4 may be used. In this experiment $M_{\max }=11.0 \mathrm{mV}$ and $\mathrm{V}_{1}=2.0 \mathrm{mV}$.

The largest $\mathbf{H}$-reflex-that is, $\mathbf{H}^{\prime \prime}$-was observed:after a stimulus of $70 \mathrm{~V}$ and was $5.5 \mathrm{mV}$. Since the corresponding $M$ wave was large $(6.9 \mathrm{mV})$ we may use this as $\mathbf{M}^{\prime}$ and $\mathbf{H}^{\prime \prime}$ as $\mathbf{H}^{\prime}$. Hence, substituting in equation (ii),

$$
P=\frac{5 \cdot 5}{11 \cdot 0-6 \cdot 9 \frac{(5 \cdot 5-2 \cdot 0)}{5 \cdot 5}}=83 \%
$$

This result is in fair agreement with the value of $73 \%$ determined previously. However, since $\mathrm{H}^{\prime}$ N 
was used as an approximation of $H_{\max }$ in the denominator, the true value of $\mathbf{P}$ will actually be rather larger than the calculated result.

\section{APPENDIX REFERENCES}

Bigland, B., and Lippold, O. C. J. (1954). Motor unit activity in the voluntary contraction of human muscle. J. Physiol. (Lond.), 125, 322-335.
Clamann, H. P. (1970). Activity of single motor units during isometric tension Neurology (Minneap.), 20, 254-260.

DasGupta, A., and Simpson, J. A. (1962). Relation between firing frequency of motor units and muscle tension in the human. Electromyography, 2, 117-128.

Táboříková, Helena, and Sax, D. S. (1968). Motoneurone pool and the H-reflex. J. Neurol. Neurosurg. Psychiat., 31, 354-361. 